\title{
Introduction: Decentralising Service Delivery? Evidence and Policy Implications
}

\section{Mark Robinson}

\section{Introduction}

Does the devolution of responsibility for service provision to elected local authorities improve the delivery of services to the poor? This is the major challenge of democratic decentralisation and a key benchmark by which its effectiveness should be assessed. Many governments across the developing world are engaged in ambitious efforts to devolve power and resources to local bodies which are increasingly assuming responsibility for managing the delivery of health, education and other essential services to poor people. Decentralised service delivery is now a key determinant of the scope for less-developed countries to achieve the Millennium Development Goals since many of these goals are premised on outcomes that are increasingly within the realm of responsibility of elected local governments.

While many adherents of decentralisation value its potential to increase accountability and participation at the local level, for poor people the critical litmus test lies in the scope for decentralisation to deliver improvements in services and material well-being.

Improvements in democratic accountability and better service delivery outcomes are not mutually exclusive but can have complementary and mutually reinforcing effects. The problem is that decentralisation policy initiatives are often premised on strengthening local democracy without considering fully the conditions under which service delivery improvements can be achieved. The challenge confronting proponents of decentralisation is that the evidence to support the case for decentralised service delivery is fragmentary and inconsistent and the conditions for successful devolution of services are poorly understood. The articles in this IDS Bulletin seek to throw light on these issues by marshalling evidence on service delivery outcomes from a range of developing countries that are engaged in a process of democratic decentralisation and highlighting the implications for designing reforms that maximise the prospects for improvements in the quality and access of services for the poor.

\section{Decentralising service delivery: assumptions and challenges}

Most efforts to promote democratic decentralisation are premised on the assumption that local governments will be more responsive to the needs of the citizens and take their preferences into account in determining the type of services to be provided, the level of resources required, and the optimal means of ensuring effective delivery. Such efforts are also predicated on the expectation that power and responsibilities will be devolved by benign central governments to elected local bodies that are accountable and responsive to their constituents. $A$ further assumption is that financial resources will be available to support the provision of services at the local level through a combination of central government fiscal transfers and local taxation. Finally, most decentralisation initiatives assume that local administrative capacity will be adequate to deliver the expected increase in the production of local services.

However, as the articles in this IDS Bulletin demonstrate, these supportive conditions are often absent in many contexts in which decentralisation is taking place. For this reason, efforts to improve the delivery of health, education, drinking water and local infrastructure through elected local governments are often destined to fail. The evidence presented here provides little succour to adherents of decentralised service delivery by showing there are very few cases where equity and efficiency 
outcomes have improved as a result of decentralisation. Evidence of sustained improvement is very slight and is usually highly context specific, with improved outcomes resulting from a combination of locally supportive conditions. The articles in this IDS Bulletin draw attention to some improvements in service delivery outcomes in Colombia and Kerala and in the health sector in parts of Asia and Africa. But there is little convincing evidence from these articles and wider experience to show that education outcomes are improved through decentralisation.

In most cases reported from Africa, Asia and Latin America the quality of public services has either declined or remained unchanged as a consequence of democratic decentralisation. The evidence collated and reviewed in this IDS Bulletin suggests that decentralised service delivery has not improved poor people's access and improvements in quality have not resulted from a transfer of power and responsibilities to local authorities. Decentralisation also accentuates horizontal inequalities between richer and poorer areas as a consequence of differential levels of administrative capacity and ability to raise local resources. From the evidence summarised by Conyers, with some minor exceptions, the experience of sub-Saharan Africa is especially disappointing with little improvement in the quality of services provided through local governments, both to poor people and local citizens more generally, a fact confirmed by negative public perception of decentralisation in many countries.

But this dismal evidence should not lead to the conclusion that decentralisation is inimical to achieving improvements in services that benefit the poor. Nor does it necessarily lead to the conclusion that centralised provision or deconcentration to arms-length central government agencies can ensure improved delivery, or that private and nongovernmental providers are better placed to deliver services to poor people at the local level. Moreover, efforts to decentralise service provision are often motivated in the first place by poorly performing centralised state agencies that are unaccountable and unresponsive to local people and their elected representatives in local governments. As Conyers cautions in her article, the results of decentralisation are mediated by a number of factors that lie beyond the control of elected local representatives and officials, such as the prevailing political context, the balance of power at the local level, and then lack of financial resources. Many of the problems with decentralised service delivery lie in the design and implementation of reform initiatives and insufficient attention to the feasibility of achieving major improvements without commensurate changes in broader governance structures and underlying socioeconomic conditions.

A further difficulty in coming to definitive conclusions on the potential for decentralisation to deliver improved outcomes is that the evidence is weak, partial and inconsistent. This finding emerges as a clear theme in the contributions by Conyers and Robinson. The case study evidence and survey data in this IDS Bulletin adds considerably to the existing knowledge base and our understanding of the problems encountered in decentralised service provision. But the contributors acknowledge that it is difficult to arrive at hard and fast conclusions in the absence of comprehensive baseline or control data on the state of service delivery at the inception of decentralised service delivery initiatives. The article by Mohmand and Cheema on the decentralisation reforms in Pakistan is one of the very few examples where such data has been collected. In most cases, the data draws on particular sectors for specific time periods and with limited geographical coverage which frustrates the task of generalisation. $A$ related problem is that the available data does not break down outcomes by socioeconomic status, gender, age or ethnicity which obscures the differential impact of decentralised service delivery on the quality and access of services. The article by Shankland and Athias on the decentralisation of health services to movements representing indigenous peoples in Brazil is a rare example of one such study. Finally, it is difficult to disentangle the differential effects of decentralisation from other parallel processes such as economic stabilisation and privatisation which have respectively resulted in fiscal austerity and reduced state provision of services. As highlighted by Robinson, for many Latin American countries in the 1980s, the combination of decentralisation with structural adjustment and privatisation proved disastrous in terms of service delivery outcomes for poorer people and regions.

\section{Decentralising service delivery: evidence and insights}

The various contributions in this IDS Bulletin provide fresh data and review available evidence on the 
impact of decentralised service delivery in local jurisdictions in Africa, Asia and Latin America. The articles by Conyers and Robinson respectively offer broader comparative reviews from Africa and developing countries as a whole while the other five articles draw on the experience of individual countries. The coverage ranges from country-level reviews in Mexico (Salazar) and Cambodia (Spyckerelle and Morrison), through to large-scale survey and comparative case study evidence from decentralisation in India (Johnson et al.) and Pakistan (Mohmand and Cheema), and the experience of indigenous communities in Brazil (Shankland and Athias). In gathering evidence they draw on original survey data, case study research and published secondary materials. The articles cover a range of service sectors but with a particular focus on health, education, drinking water and sanitation, as well as local infrastructure, with considerable variation in the form and extent of decentralisation and availability of resources. Most of the empirical material covers the period of democratic decentralisation from the late 1980s and 1990s, with reference to earlier episodes of administrative decentralisation under centralised and authoritarian governments.

In his contribution to this IDS Bulletin, Robinson surveys the empirical evidence in the secondary literature on the impact of decentralisation on service delivery, drawing on examples and case material from Latin America, Africa and Asia. He finds that the comparative evidence on equity and efficiency outcomes is very limited and uneven in coverage, rendering the task of generalisation difficult. The available evidence suggests that the consequences for equity and efficiency are largely negative, with poorer people and regions being disadvantaged by decentralisation reforms or receiving a much lower share of the resulting benefits of improved service delivery. Contrary to theoretical expectations, there is little evidence to suggest that the quality of services improves with decentralisation, which means that local preferences do not automatically translate into improved targeting and delivery. While decentralisation can contribute to improved participation and accountability, it is generally not delivering improved service delivery outcomes. This does not invalidate the potential of decentralisation to improve the delivery of quality services to the poor or to reduce inter-regional disparities. Robinson argues that a number of supporting conditions are required to enable decentralisation to deliver on this potential, which includes political commitment, political mobilisation of the poor, institutionalised participation and accountability mechanisms, the availability of adequate financial resources, and technical and managerial capacity in local governments.

In her article, Conyers focuses on African experience of decentralisation and reviews the evidence on service delivery outcomes available from a variety of countries and sectors. She also finds that, despite some isolated examples of success, decentralisation has not had a significant positive impact on the quality of public services in the region. However, she argues that the main reason for poor outcomes stems from the fundamental characteristics of contemporary African states than decentralisation as such. These include the centralisation of power, weak structures of accountability, and lack of countervailing pressure from civil society. For these reasons, African governments have largely been reluctant to devolve power and finance to local governments, which consequently lack the capacity and resources to deliver improved services. Conyers concludes that the problems of decentralisation cannot be addressed in isolation from wider problems of governance prevailing in many African countries, and therefore have to be addressed as part of a slow and gradual process of state-building.

Turning to the first of the Asian cases, Johnson et al. examine the impact that local governance structures have on the ability of sub-national governments to implement social policy in two states of India, Madhya Pradesh and Andhra Pradesh. They find significant differences in the functioning of decentralised local bodies in the two states which have a bearing on the implementation of credit delivery programmes for the poor. In Madhya Pradesh, which had progressed further with legislation governing the devolution of powers and responsibilities, the government implemented its self-employment and microcredit programme through elected local councils (panchayats). In contrast, the government of Andhra Pradesh chose to implement its group savings scheme through selfhelp groups formed by poor rural women under the supervision of officials in local government administrations. Based on extensive field research in the two states, the authors find that rates of satisfaction were much higher among members of self-help groups in Andhra Pradesh than among microcredit beneficiaries in Madhya Pradesh, and 
that perceived levels of corruption were much lower in the former. The authors also report that levels of participation in village assemblies (gram sabhas) were much higher in Andhra Pradesh, explained in part by the incentives generated by the microcredit programme and the closer spatial proximity between villagers and local government officials.

The personal involvement of the elected heads of local councils (sarpanches) in Madhya Pradesh in determining eligibility and access to government schemes was found to give rise to patronage in beneficiary selection, while in Andhra Pradesh the heads of elected councils lacked such discretion, with local government officials primarily responsible for selection, monitoring and implementation. These findings demonstrate that devolving power and responsibility to elected local councils in India may not produce the improvements in service delivery anticipated by proponents of democratic decentralisation without commensurate improvements in local accountability. Rather, the authors highlight the value of close interactions between local self-help groups representing the collective interests of poor women and line department officials operating at the local level in which the scope for graft was minimised by the design of the programme and the type of benefits that accrued to the participants in the scheme.

Mohmand and Cheema analyse the extent to which decentralisation reforms introduced in 2001 have been effective in improving the magnitude and provision of health and education services in rural Pakistan. Survey data from four villages in Faisalabad district of Punjab province gathered two years after the introduction of the reforms reveal that while the provision of targeted sanitation and sewerage services has increased substantially, the vast majority of respondents in the sample villages report that the delivery of universal health and education services has either remained unchanged or has worsened. These results are confirmed by a national social audit that used a baseline survey to track improvements in service delivery. Utilisation of government health services has declined dramatically because of shortages in the availability of medicines and doctors while those who were able to afford to do so opted for private health provision on the basis of availability rather than considerations of quality. Mohmand and Cheema find a similar pattern with state-provided primary education, where the majority of respondents report no improvement in teacher attendance or in school facilities since the decentralisation reforms. This is especially marked for girls' primary schools where teacher attendance is worse than for equivalent boys' schools, but where alternative options for private schooling are far less prevalent or accessible. An important consequence of the reforms is that quality and equity in the local provision of public services has worsened, and that smallholders and low caste citizens and their girl children are especially vulnerable as they cannot access alternative options. The authors locate these problems in accountability failures in the design of the new decentralised system and the consequent inability of citizens to hold local service providers to account for the shortcomings in the provision of universal services.

In the third Asian case considered in this IDS Bulletin, Spykerelle and Morrison examine the approach taken in Cambodia to the delivery of small-scale local infrastructure through newly empowered communes under the provisions of the 2001 legislative framework for devolved governance. A central objective of these reforms was to improve local infrastructure and access to services, as well as to promote participation and good governance at the local level. Based on successful experience with discretionary funding before the new legislation came into force, a special Commune Fund was established to which the communes submit bids for local infrastructure development in the form of funding for the construction and repair of roads, bridges, irrigation works, water and power supply, markets, schools and health centres, which in turn could improve the provision of basic services.

Since 2003, one third of Cambodia's population is estimated to have benefited from these investments. While it is too early to determine the effectiveness of these commune-level investments, Cambodia has laid the foundations for decentralised service delivery by establishing district-level planning and administrative arrangements to oversee local implementation and has created consultation mechanisms to ensure that the interests of the poor are represented in commune development planning processes. A key obstacle facing the successful decentralisation of service provision in Cambodia is the limited financial resources available to the communes for local infrastructure investments (a little over US\$1 per capita), capacity constraints at the 
commune level, and the limited scope for mobilising local financing. The remit of communes in local service provision is also restricted in focus. Health and education still remain the responsibility of central line departments and the communes have no direct role in the implementation of these services under present legislative provisions. However, Cambodia has created the legislative and administrative foundations on the basis of which further devolution of responsibility for service provision could occur, provided that commensurate resources and capacitybuilding investments are provided by the central government.

Coming to the first of two Latin American cases, Salazar examines the lessons emerging from Mexico's experience of decentralisation for the delivery of essential public services since the late 1990s. There has been a major shift in responsibility from centralised government provision to the present-day situation in which state and municipal governments are responsible for providing the majority of services in health, education and social infrastructure. But the evidence on changes in the delivery of public services does not point to a positive picture from the perspective of equity and efficiency. In particular, there are horizontal imbalances in levels of provision and service delivery outcomes between the richer and more disadvantaged parts of the country and among different sections of the population. Education achievement has not improved with decentralisation while significant disparities remain among social groups in terms of years of schooling. Considerable inefficiencies arise from unclear demarcation of responsibilities between state and federal governments. In the health and education sectors there are significant disparities in the availability of resources for service provision between different states. Increased funds have been made available to finance social infrastructure in the municipalities but the evidence suggests that there is no discernable relationship between the resources expended and resultant improvements in service delivery. Salazar identifies two key problems that contribute to poor service delivery, namely the weak accountability of public officials responsible for service delivery and the high degree of fiscal centralisation, both of which inhibit the scope for improved outcomes.

The decentralisation of healthcare in Brazil is the focus of the contribution by Shankland and Athias, with a particular focus on the role of indigenous peoples' movements in the delivery of health services. Indigenous peoples suffer from much worse health problems than the average Brazilian citizen, with higher rates of infant mortality and high rates of morbidity from infectious diseases. The Brazilian government's efforts to decentralise healthcare provision to municipalities and special indigenous health districts in the 1990s was designed to tackle problems of centralisation and exclusion. But despite improvements in immunisation coverage and other health indicators, efforts to subcontract the provision of healthcare services in indigenous health districts to non-governmental organisations (NGOs), church groups and indigenous organisations did not prove successful, with continued high rates of morbidity among indigenous peoples from preventable diseases. Shankland and Athias examine the experience of decentralised healthcare in a region mainly inhabited by indigenous peoples through a case study of the Rio Negro region in the far northwest of the Brazilian Amazon, where an indigenous peoples' movement assumed management responsibility for health services. However, the movement continued to operate within the technical parameters of state health provision, with priorities and resource allocations largely determined by non-indigenous health professionals in line with central government policies. While the efficiency of healthcare provision improved under indigenous management, it faced a series of difficulties caused by delayed financial transfers and was unable to preserve an adequate level of health services which resulted in problems with uneven drug supplies and erratic staff attendance in health centres. Hence, while the principle of decentralising healthcare delivery to indigenous management was initially viewed as a welcome development, it ultimately proved unable to achieve any significant impact on the nature of the decentralised service given the constraints operating in the wider healthcare system.

\section{Lessons and implications}

The implications of the various articles in this IDS Bulletin are of considerable significance for research and policy. These emanate from a remarkably consistent set of findings based on the empirical evidence gathered by the contributors from a range of countries and sectors. These are as follows: (1) the consequences of democratic decentralisation in terms of service delivery outcomes are largely 
negative, (2) poor and marginalised people have not generally experienced improved access and service quality under democratic decentralisation; and (3) improved outcomes are contingent on a supportive set of conditions and mediating factors, some of which lie outside the control of elected local governments.

These findings raise important implications for research. The dearth of systematic, robust and comparative evidence on decentralised service delivery outcomes is a striking gap in knowledge. Existing research remains partial, limited and context specific. Knowledge on what works well, where, how and why is still fragmentary. The implications of decentralisation for service delivery in different sectors in a range of political and socioeconomic contexts are far from clear. There are fewer areas of development policy that are more in need of research than strengthening the evidence base to measure the impact of policies designed to deliver services to poor people through elected local governments.

The most immediate policy implication is an urgent need to reappraise what democratic decentralisation can realistically be expected to deliver in terms of improved service delivery. In some contexts, the expectations may simply be excessive, and limitations of resources and administrative capacity mean that elected governments may not be well placed to take on the increased responsibilities that have been devolved to them. Countries emerging from conflict and protracted civil war may not be in a position to rapidly devolve services to local governments. Equitable service delivery outcomes are unlikely to come about when power is deeply contested and powerful social groups control resources and dominate local politics, since these are precisely the conditions that give rise to élite capture in decentralised service delivery. Efforts to decentralise service delivery in such environments are likely to fail, especially if they result from hasty and poorly designed interventions that are intended to generate rapid results in the form of improved equity and efficiency.

More stable political contexts accompanied by steady economic growth and with relatively capable local governments offer a more conducive environment for the devolution of power and resources which in turn are indispensable requirements for successful decentralisation of service delivery. Devolution of responsibility for service provision without strengthening local state capacity to produce or to coordinate delivery by non-state actors at the local level produces inefficient and negative outcomes. Inadequate resourcing of services through restricted fiscal transfers to local authorities from central governments and commensurate local tax-raising powers limits the scope and capacity to generate sufficient funds for adequate levels of service provision. Delegation of responsibility to non-state and private sector providers can make up for some of the shortfall in provision but this is not a substitute for enhanced local state capacity and adequate levels of resources. Political commitment, effective channels of accountability and effective oversight of service provisioning by local non-state actors are all recognised to be essential ingredients for efficient and equitable provision. Finally, even though concepts of devolution and local governance have a long pedigree, democratic decentralisation is still a relatively new phenomenon in most less-developed countries and positive results will take a long time to mature. As with other types of governance reforms, short-term and time-bound interventions will not bring about the desired improvements in service delivery outcomes. Steady, incremental and wellresourced initiatives that build capacity and increase accountability are the surest route to realising the promise of democratic decentralisation. 